\title{
Densidade e Características Morfológicas de Plantas de Picão-Preto na Previsão de Perdas de Rendimento de GRÃOS DE SOJ A POR INTERFERÊNCIA ${ }^{1}$
}

\author{
Density and Morphological Plant Characteristics of Beggarticks in Predicting Soybean Grain \\ Yield Losses Due to Interference
}

FLECK, N.G. ${ }^{2}$ RIZZARDI, M.A. ${ }^{3}$ AGOSTINETTO, D. ${ }^{4}$ e BALBINOT JR., A.A. ${ }^{4}$

\begin{abstract}
RESUMO - A utilização de sistemas para manejo integrado de plantas daninhas depende da habilidade em se prever o impacto da infestação de plantas daninhas no potencial de rendimento de grãos da cultura. O objetivo deste trabalho foi comparar diferentes variáveis explicativas para uso no modelo da hipérbole retangular, a fim de identificar aquela que forneça melhor previsão da interferência de picão-preto (Bidens pilosa e Bidens subalternans, em infestações mistas) em soja. Foram realizados experimentos em dois ambientes, localizados em Passo Fundo e Eldorado do Sul, RS. Utilizaram-se densidades variáveis de picão-preto e três épocas de semeadura da soja (3, 7 e 11 dias após a dessecação da cobertura vegetal das áreas). Avaliou-se a densidade das plantas daninhas aos 20 e 30 dias após a emergência da soja (DAE) e na pré-colheita e características morfológicas de plantas de picão-preto, como densidade de folhas, área foliar e cobertura foliar do solo aos 20 DAE. Constatou-se que a variável explicativa densidade de plantas de picão-preto propiciou ajustes satisfatórios do modelo; no entanto, ela não integra os efeitos de ambientes e de épocas de semeadura da cultura, diferentemente do que ocorreu para as características morfológicas. Dentre estas, destacam-se a densidade de folhas e a de área foliar como as de maior potencial de utilização como variáveis explicativas na previsão da perda de rendimento de grãos de soja por interferência de picão-preto.
\end{abstract}

Palavras-chave: Bidens pilosa, Bidens subalternans, competição, modelagem, variáveis explicativas.

\begin{abstract}
The adoption of integrated weed management systems depends on the ability to foresee the impact of weeds on crop grain yield potential. The objective of this research was to compare different explicative variables to use in adjusting the rectangular hyperbolic model, in order to identify which one would provide best prediction of beggarticks (Bidens pilosa and Bidens subalternans, occurring in mixed infestations) interference on soybean crop. Experiments were carried out in two environments, located at Passo Fundo and Eldorado do Sul, RS, Brazil. Various beggartick densities and three soybean seeding times 13,7 , and 11 days after cover crops desiccation) were used. Evaluations carried out were beggartick densities 20 and 30 days after soybean emergence (DAE) and at crop harvesting time, and weed plant morphological characteristics, such as leaf density, leaf area, and soil leaf coverage, all performed 20 DAE. It was detected that the explicative variable beggartick plant density provided satisfactory adjustments of the equation model; nevertheless, it does not integrate the effects of environments nor of crop seeding time, differently of what happened with the morphological characteristics. Among them, leaf density and leaf area showed greater potential for use as explicative variables in predicting soybean grain yield losses due to beggartick interference.
\end{abstract}

Key words: Bidens pilosa, Bidens subalternans, competition, modeling, explicative variables.

Recebido para publicação em 1/4/2002 e na forma revisada em 7/8/2002.

2 Eng.-Agr., Ph.D., Professor do Dep. de Plantas de Lavoura da Faculdade de Agronomia da Universidade Federal do Rio Grande do Sul - UFRGS, bolsista do CNPq. ${ }^{3}$ Eng.-Agr., Dr., Professor da Faculdade de Agronomia e Medicina Veterinária da Universidade de Passo Fundo, Caixa Postal 611, 99001-970 Passo Fundo-RS. ${ }^{4}$ Eng.-Agr., M.S., Aluno do Programa de PósGraduação em Fitotecnia da UFRGS.

Planta Daninha, Viçosa-MG, v.20, n.2, p.169-179, 2002 


\section{INTRODUÇÃO}

O sucesso em utilizar programas de manejo relacionados com níveis de dano econômico depende da habilidade de se prever a função de dano, ou seja, o impacto da população de ervas no potencial de rendimento da cultura. Diversos métodos foram sugeridos para prever a relação entre densidade de ervas e rendimento da cultura (Bussler et al., 1995). A maioria dos métodos para relacionar rendimento e densidade baseia-se na composição média da comunidade (Kropff \& Spitters, 1991). Entretanto, como as populações de plantas com freqüência são compostas por uma hierarquia de indivíduos, com alguns dominantes de grande tamanho e outros constituídos por elevado número de plantas pequenas suprimidas, a composição média de plantas não representa a planta mais comum numa população (Bussler et al., 1995). Segundo esses autores, tomando-se a composição média das plantas através de todos os indivíduos numa área, pode-se obscurecer os efeitos das concentrações de recursos espacialmente heterogêneos, o que alteraria o resultado das interações competitivas.

As funções de dano, baseadas na densidade de ervas, normalmente ignoram as diferenças morfológicas existentes entre os indivíduos. Os resultados encontrados na bibliografia realçam as limitações associadas ao uso da densidade de ervas como base para previsão das perdas de rendimento, pois a avaliação da densidade não leva em conta a época relativa de emergência e tampouco as variações no tamanho das ervas (Weaver, 1991; Vitta et al., 1993; Lutman et al., 2000). Além disso, Lutman et al. (1996) salientam que as previsões baseadas na densidade e na época de emergência não consideram o vigor relativo da cultura e das ervas, que são parâmetros importantes na compreensão da interface competitiva das espécies daninhas. Portanto, o modelo perda de rendimento-densidade de ervas só será útil se for possivel derivar uma função de dano com base em algum aspecto relacionado ao tamanho das ervas, em vez de ou em acréscimo à densidade, melhorando, conseqüentemente, a previsão das perdas de rendimento da cultura causadas por ervas (Weaver, 1991).

Medidas associadas ao tamanho das plantas e à estrutura do dossel em geral integram os efeitos competitivos, independentemente dos recursos pelos quais as plantas competem (Vitta et al., 1993). Uma das medidas que delimitam o tamanho de planta é sua massa seca. A relação entre massa seca de plantas daninhas e redução do rendimento de grãos é razoavelmente bem ajustada pelo modelo de regressão exponencial (Oliver et al., 1976). De forma semelhante, Spadotto et al. (1992) constataram que acréscimos na massa seca das ervas correlacionam-se com reduções no rendimento de grãos. Para Oliver et al. (1976), essa característica foi a melhor indicadora da competição interespecífica ocorrida. No entanto, para Lutman et al. (1996), o ajuste da regressão entre massa seca e rendimento não foi tão satisfatório quanto o obtido com a densidade de ervas; contudo, a variação verificada entre anos tendeu a ser menor com o uso da massa seca, e o erro-padrão variou menos para as culturas analisadas.

De outra parte, características associadas ao dossel foliar podem englobar todos os componentes das ervas envolvidos na competição, incluindo espécies, tamanho das plantas, densidades e épocas de sua emergência, segundo Aldrich (1987). Resultados obtidos com simulação de dados demonstraram haver estreita relação entre área foliar e perda de rendimento sobre ampla faixa de densidades de ervas e épocas de sua emergência em relação à cultura (Kropff \& Spitters, 1991; Kropff \& Lotz, 1992). Dessa forma, seria mais apropriado caracterizar a infestação de ervas com medidas de área foliar no início da estação de crescimento, pois a intensidade competitiva de uma espécie é fortemente determinada pela sua participação na área foliar total no momento em que o dossel se fecha e inicia a competição interplantas (Kropff \& Spitters, 1991). No entanto, apesar de a variável área foliar ser promissora na caracterização da competição, o dispêndio de tempo na sua determinação dificulta sua implementação. Além disso, a correlação de área foliar com outras variáveis é difícil de obter, visto que, na maioria das vezes, constitui-se em avaliação destrutiva (Ngouajio et al., 1999). Nesse sentido, foram sugeridas cobertura foliar, definida como a proporção do solo (porcentagem) ocupada pela projeção vertical da parte aérea de uma espécie (Lotz et al., 1994), e densidade de folhas (Weaver, 1991). 
O objetivo deste trabalho foi comparar diferentes variáveis explicativas para uso no modelo da hipérbole retangular, a fim de identificar aquela que forneça melhor previsão da interferência de picão-preto (Bidens pilosa e Bidens subalternans, em infestações mistas) em soja.

\section{MATERIAL E MÉTODOS}

Dois experimentos foram conduzidos em campo, sendo um na Faculdade de Agronomia e Medicina Veterinária da Universidade de Passo Fundo, na região fisiográfica do Planalto Médio do Rio Grande do Sul, e outro na Estação Experimental Agronômica da Universidade Federal do Rio Grande do Sul (EEA/UFRGS), na região fisiográfica da Depressão Central. O primeiro experimento foi conduzido durante a estação de crescimento 1998/99, em Passo Fundo (ambiente 1), e o segundo o foi $\mathrm{em}$ 1999/00, em Eldorado do Sul (ambiente 2). Os solos das áreas experimentais são classificados como Latossolo Vermelho Distrófico típico e Argissolo Vermelho Distrófico típico, para Passo Fundo e Eldorado do Sul, respectivamente (Empresa...-EMBRAPA, 1999).

O delineamento experimental utilizado nos dois experimentos foi completamente casualizado, com os tratamentos sendo dispostos em esquema fatorial, com uma repetição. Nos dois ambientes, os tratamentos representativos do fator A constaram de densidades (Bidens pilosa e $B$. sulbalternans, em infestações mistas) e os do fator B consistiram de épocas de semeadura de soja em relação à data de dessecação da cobertura vegetal existente nas áreas. Nos dois ambientes, a semeadura da soja foi realizada aos 3, 7 e 11 dias após a dessecação (DAD).

As densidades de ervas foram alocadas aleatoriamente no campo, de acordo com niveis populacionais de ervas encontrados naturalmente na área. No ambiente 1 , utilizaram-se 17 unidades em cada época de semeadura, cujas densidades variaram entre 1 e 180 plantas $\mathrm{m}^{-2}$, perfazendo o total de 51 unidades com infestação. No ambiente 2, foram utilizadas 10 unidades em cada época de semeadura, com densidades de picão-preto variáveis de uma a 110 plantas $\mathrm{m}^{-2}$, totalizando 30 unidades com infestação. Nos dois ambientes, mantiveramse quatro a cinco unidades com ausência de ervas, em cada uma das épocas de semeadura da soja. Cada unidade experimental mediu $6 \mathrm{~m}^{2}(2 \times 3 \mathrm{~m})$, constando de cinco fileiras de soja espaçadas em $0,4 \mathrm{~m}$.

Os experimentos foram implantados utilizando-se o sistema de semeadura direta, em áreas com cobertura vegetal formada por aveiapreta (Avena strigosa). O manejo da cobertura foi realizado com os herbicidas glyphosate (900 g de equivalente ácido ha-1) e 2,4-D (670 g de equivalente ácido $\mathrm{ha}^{-1}$ ), procedido por ocasião do florescimento das plantas de aveiapreta. Em ambos os experimentos foi realizada uma segunda dessecação, com o herbicida paraquat (300 $\left.\mathrm{g} \mathrm{ha}^{-1}\right)$, que foi feita três dias antes da primeira época de semeadura da soja, para eliminar as ervas que não foram controladas com a primeira dessecação e também aquelas que emergiram no período entre a primeira e a segunda dessecação.

A adubação do solo foi realizada por ocasião da semeadura da soja, no ambiente 1 , por meio da distribuição de $300 \mathrm{~kg} \mathrm{ha}^{-1}$ da fórmula 05-20-30 e, no ambiente 2 , através da distribuição de $340 \mathrm{~kg} \mathrm{ha}^{-1}$ da fórmula 05-25-25. Em ambos os experimentos utilizou-se o cultivar de soja Embrapa 66, de ciclo médio de desenvolvimento, o qual foi estabelecido na densidade de 400 mil plantas ha-1.

O controle de ervas gramíneas foi obtido com o herbicida clethodim ( $\left.120 \mathrm{~g} \mathrm{ha}^{-1}\right)$, acrescido do adjuvante Assist usado a 0,5\% volume/ volume. Durante a condução dos experimentos foram realizadas suplementações hídricas por meio de irrigações por aspersão, a fim de se garantir adequado desenvolvimento à cultura.

As avaliações das densidades de picãopreto ocorreram 20 dias após a emergência (DAE) da soja, em área de $1,0 \mathrm{~m}^{2}$ por parcela, dividida em dois locais de cada unidade. No ambiente 2 foram feitas contagens adicionais das populações da erva aos $30 \mathrm{DAE}$ e na précolheita da soja. A massa seca das ervas foi avaliada aos $20 \mathrm{DAE}$ e, também, na pré-colheita da soja, apenas no ambiente 2 . Para obtenção da massa seca das ervas, fez-se a coleta das partes aéreas em duas áreas de $0,5 \mathrm{~m}^{2}$, numa extremidade de cada parcela. A secagem do material deu-se em estufa com circulação forçada de ar à temperatura de $60{ }^{\circ} \mathrm{C}$, até se obter peso constante. 
As determinações de área foliar e densidade de folhas das ervas foram feitas aos 20 DAE, a partir das plantas coletadas para determinação da massa seca. A área foliar foi determinada em todas as plantas colhidas, com auxílio de um integrador eletrônico de área foliar. Depois disso, fez-se a contagem do número de folhas por planta, com o que se calculou a densidade de folhas por indivíduo. A cobertura foliar pelo dossel das ervas foi avaliada visualmente, utilizando-se escala percentual, em que a nota zero correspondeu à ausência de cobertura foliar sobre o solo e a nota 100 significou cobertura completa do solo. No ambiente 1, a avaliação foi realizada por dois avaliadores que atuaram de modo independente, os quais atribuíram individualmente suas notas, que foram somadas para obtenção das respectivas médias. No ambiente 2 foi realizada uma segunda avaliação visual da cobertura foliar por ervas por ocasião do florescimento da soja.

O rendimento de grãos da soja foi determinado em área de $3,0 \mathrm{~m}^{2}$ (1,2 x 2,5 m), englobando as três fileiras centrais das parcelas. A partir dos dados de rendimento foram calculadas as perdas percentuais em relação às parcelas mantidas livres de ervas. Aos dados de porcentagens de perda de rendimento foi ajustado o modelo de regressão não-linear da hipérbole retangular proposto por Cousens (1985): $\mathrm{P}_{\mathrm{r}}=$ $\left(\mathrm{i}^{*} \mathrm{X}\right) /(1+((\mathrm{i} / \mathrm{a}) * \mathrm{X}))$, em que: $\mathrm{P}_{\mathrm{r}}=$ perda de rendimento (\%); $\mathrm{X}=$ densidade de plantas, massa seca, área foliar, densidade de folhas ou cobertura foliar por ervas; $i=$ porcentagem de perda de rendimento por unidade de erva quando sua densidade se aproxima de zero; e $\mathrm{a}=$ porcentagem de perda de rendimento quando a densidade de ervas tende ao infinito.

O ajuste do modelo aos dados foi realizado usando-se o procedimento Proc Nlin do programa computacional SAS (SAS, 1989). O modelo da hipérbole foi ajustado considerando-se as variáveis explicativas individualmente, em cada ambiente e dentro de cada ambiente para cada época, independentemente de ocorrer interação entre ambientes e épocas. Esse procedimento foi adotado para permitir a comparação dos modelos ajustados, a qual se deu através da comparação dos coeficientes de determinação $\left(R^{2}\right)$ e da soma de quadrados do resíduo (SQR). A escolha do melhor modelo de ajuste baseou-se no maior valor de $\mathrm{R}^{2}$ e no menor valor de SQR.

Após a escolha do modelo com melhor capacidade previsiva, fez-se a comparação dos modelos ajustados entre ambientes, procedendo-se, inicialmente, à verificação de homogeneidade de variâncias pelo teste de Bartlett (Gomez \& Gomez, 1984). Nos casos em que houve homocedasticidade, foi realizada comparação entre ambientes e entre épocas, utilizando-se método preconizado por Chow (Florez et al., 1999).

Aos valores de densidades de plantas obtidos no ambiente 2 em diferentes épocas foram ajustados modelos polinomiais e da hipérbole retangular. Além da análise de regressão, procedeu-se à análise de correlação linear simples entre as variáveis explicativas avaliadas dentro de cada ambiente.

\section{RESULTADOS E DISCUSSÃO}

O uso da densidade de plantas de picãopreto, avaliada aos $20 \mathrm{DAE}$, como variável explicativa do modelo de previsão das perdas de rendimento de grãos de soja permitiu ajustes satisfatórios nos dois ambientes estudados (Tabela 1). No entanto, observou-se que a precisão do ajuste variou tanto entre ambientes como entre épocas de semeadura dentro de cada ambiente (Tabela 2). À medida que se atrasou a semeadura da soja em relação à dessecação da cobertura vegetal, em geral diminuíram os valores de $\mathrm{R}^{2}$ e aumentaram os valores de soma dos quadrados do resíduo (SQR), o que caracterizou menor precisão de ajuste pelo modelo utilizado em resposta àquele fator (Tabela 1).

As diferenças entre épocas de semeadura na capacidade de ajuste do modelo podem estar associadas à modificação na densidade de plantas de picão-preto, observada ao longo da estação de crescimento no ambiente 2 (Figura 1). Nesta figura, observa-se existir relação linear entre densidade inicial da erva aos 20 DAE e densidade aos $30 \mathrm{DAE}$, para as três épocas de semeadura da soja. Contudo, a relação entre densidade inicial da erva e densidade na pré-colheita da soja alterou-se em função de épocas de semeadura da cultura. Nas duas primeiras épocas (3 e 7 DAD), a relação apresentou comportamento hiperbólico, ou seja, até populações iniciais de aproximadamente 
24 plantas para semeadura aos 3 DAD e 15 plantas para a de $7 \mathrm{DAD}$, a relação seguiu a observada aos $30 \mathrm{DAD}$. A partir dessas populações, as relações mantiveram-se constantes, provavelmente devido à mortalidade de plantas em densidades maiores, que ocorreu até o final do ciclo da soja. Na semeadura aos 11 DAD, as relações da densidade inicial com as densidades aos 30 DAE e na pré-colheita da soja seguiram a mesma tendência, o que indica a possibilidade de ter ocorrido menor mortalidade de plantas; porém, é importante salientar que as densidades iniciais máximas nessa época de semeadura foram inferiores a 50 plantas $\mathrm{m}^{-2}$.

Tabela 1 - Parâmetros estimados e ajustes obtidos para perdas de rendimento de grãos de soja em função de diferentes variáveis explicativas da erva picão-preto e de épocas de semeadura da soja, em Passo Fundo-RS, 1998/99 (ambiente 1), e em Eldorado do Sul-RS, 1999/00 (ambiente 2)

\begin{tabular}{|c|c|c|c|c|c|}
\hline \multirow{2}{*}{$\begin{array}{l}\text { Variável explicativa da infestação } \\
\text { de picão-preto }{ }^{1 /}\end{array}$} & \multicolumn{2}{|c|}{ Parâmetro ${ }^{2 /}$} & \multirow{2}{*}{$\begin{array}{c}\text { Coeficiente de } \\
\text { determinação } \\
\left(\mathrm{R}^{2}\right)\end{array}$} & \multirow{2}{*}{$\begin{array}{l}\text { Soma dos } \\
\text { quadrados do } \\
\text { resíduo }\end{array}$} & \multirow{2}{*}{ Estatística F } \\
\hline & $\mathrm{i}$ & $\mathrm{a}$ & & & \\
\hline $\begin{array}{r}\text { Ambiente 1: } \\
\text { Densidade de plantas } \\
3 \mathrm{DAD}^{3 /} \\
7 \mathrm{DAD} \\
11 \mathrm{DAD}\end{array}$ & $\begin{array}{l}0,36 \\
0,94 \\
3,43\end{array}$ & $\begin{array}{l}78,2 \\
42,7 \\
42,5\end{array}$ & $\begin{array}{l}0,65 \\
0,56 \\
0,59\end{array}$ & $\begin{array}{l}1.031,6 \\
1.792,5 \\
3.524,7\end{array}$ & $\begin{array}{c}47,9 * 41 \\
36,6^{*} \\
29,6^{*}\end{array}$ \\
\hline $\begin{array}{r}\text { Massa seca } \\
3 \mathrm{DAD}^{3 /} \\
7 \mathrm{DAD}^{1} \\
11 \mathrm{DAD}^{2}\end{array}$ & $\begin{array}{l}0,58 \\
0,43 \\
1,47\end{array}$ & $\begin{array}{l}75,0 \\
75,8 \\
41,0\end{array}$ & $\begin{array}{l}0,63 \\
0,55 \\
0,37\end{array}$ & $\begin{array}{l}1.081,5 \\
1.836,6 \\
3.732,1\end{array}$ & $\begin{array}{l}45,4^{*} \\
35,5^{*} \\
27,5^{*}\end{array}$ \\
\hline $\begin{array}{r}\text { Densidade de folhas } \\
3 \mathrm{DAD}^{3 /} \\
7 \mathrm{DAD} \\
11 \mathrm{DAD}\end{array}$ & $\begin{array}{l}0,27 \\
0,21 \\
0,79 \\
\end{array}$ & $\begin{array}{l}50,0 \\
49,8 \\
46,5 \\
\end{array}$ & $\begin{array}{l}0,70 \\
0,56 \\
0,45 \\
\end{array}$ & $\begin{array}{r}879,3 \\
1.778,9 \\
3.280,7\end{array}$ & $\begin{array}{l}57,6 * \\
36,9^{*} \\
32,4^{*}\end{array}$ \\
\hline $\begin{array}{l}\text { Área foliar } \\
3 \mathrm{DAD}^{3 /} \\
7 \mathrm{DAD}^{\prime} \\
11 \mathrm{DAD}\end{array}$ & $\begin{array}{l}0,21 \\
0,17 \\
0,78\end{array}$ & $\begin{array}{l}60,7 \\
48,1 \\
44,1\end{array}$ & $\begin{array}{l}0,70 \\
0,54 \\
0,47\end{array}$ & $\begin{array}{r}868,4 \\
1.883,5 \\
3.178,6\end{array}$ & $\begin{array}{l}58,5^{*} \\
34,4^{*} \\
33,7^{*}\end{array}$ \\
\hline $\begin{array}{l}\text { Cobertura foliar } \\
3 \mathrm{DAD}^{3 /} \\
7 \mathrm{DAD}^{11 \mathrm{DAD}}\end{array}$ & $\begin{array}{l}0,64 \\
0,63 \\
0,89\end{array}$ & $\begin{array}{l}55,5 \\
52,1 \\
54,0\end{array}$ & $\begin{array}{l}0,44 \\
0,60 \\
0,35\end{array}$ & $\begin{array}{l}1.636,4 \\
1.640,8 \\
3.859,0\end{array}$ & $\begin{array}{l}27,2 * \\
40,7 * \\
26,4 *\end{array}$ \\
\hline $\begin{array}{r}\text { Ambiente 2: } \\
\text { Densidade de plantas } \\
3 \mathrm{DAD}^{3 /} \\
7 \mathrm{DAD} \\
11 \mathrm{DAD}\end{array}$ & $\begin{array}{r}0,96 \\
5,02 \\
13,53 \\
\end{array}$ & $\begin{array}{l}51,1 \\
43,6 \\
48,1 \\
\end{array}$ & $\begin{array}{l}0,89 \\
0,77 \\
0,53 \\
\end{array}$ & $\begin{array}{r}162,5 \\
560,5 \\
1.965,1\end{array}$ & $\begin{array}{l}127,5^{*} \\
57,0^{*} \\
29,5^{*}\end{array}$ \\
\hline $\begin{array}{r}\text { Massa seca } \\
3 \mathrm{DAD}^{3 /} \\
7 \mathrm{DAD}^{\prime} \\
11 \mathrm{DAD}^{2}\end{array}$ & $\begin{array}{l}0,19 \\
0,42 \\
0,81\end{array}$ & $\begin{array}{l}37,4 \\
38,7 \\
46,5\end{array}$ & $\begin{array}{l}0,80 \\
0,47 \\
0,54 \\
\end{array}$ & $\begin{array}{r}300,7 \\
1.327,5 \\
1.896,7\end{array}$ & $\begin{array}{l}66,8 * \\
21,4 * \\
30,8^{*}\end{array}$ \\
\hline $\begin{array}{l}\text { Cobertura foliar } \\
3 \mathrm{DAD}^{3 /} \\
7 \mathrm{DAD}^{11 \mathrm{DAD}}\end{array}$ & $\begin{array}{r}1,77 \\
0,43 \\
12,47\end{array}$ & $\begin{array}{l}28,6 \\
57,6 \\
48,4\end{array}$ & $\begin{array}{l}0,70 \\
0,49 \\
0,55\end{array}$ & $\begin{array}{r}439,6 \\
1.258,9 \\
1.880,5\end{array}$ & $\begin{array}{l}44,3 * \\
22,9 * \\
31,1 *\end{array}$ \\
\hline
\end{tabular}

${ }^{1 /}$ Avaliadas aos 20 dias após a emergência da soja.

$\underline{2} / \mathrm{i}=$ porcentagem de perda de rendimento por unidade da erva quando sua densidade se aproxima de zero; $\mathrm{a}=$ porcentagem de perda de rendimento quando a densidade da erva tende ao infinito.

³/Época da semeadura da soja em dias após a dessecação da cobertura vegetal.

${ }^{4 /}$ Indica significância a 5\% de probabilidade. 
Tabela 2 - Estatística F das análises comparativas entre ambientes e épocas de semeadura da soja em experimentos com picão-preto realizados em Passo Fundo-RS, 1998/99 (ambiente 1), e Eldorado do Sul-RS, 1999/00 (ambiente 2)

\begin{tabular}{|c|c|c|}
\hline \multirow{2}{*}{$\begin{array}{l}\text { Variável explicativa da infestação de } \\
\text { picão-preto }{ }^{1 /}\end{array}$} & \multicolumn{2}{|r|}{ Valor de F } \\
\hline & Comparação entre ambientes & Comparação entre épocas de semeadura da soja \\
\hline Densidade de plantas & $6,04 *$ & \\
\hline Ambiente 1 & ------ & $3,31 *$ \\
\hline Ambiente 2 & ------ & $4,71 *$ \\
\hline Massa seca & $2,36^{\mathrm{ns}}$ & $0,88^{\mathrm{ns}}$ \\
\hline Área foliar & ------ & $2,43^{\mathrm{ns}}$ \\
\hline Densidade de folhas & ------ & $1,05^{\mathrm{ns}}$ \\
\hline Cobertura foliar & $8,06^{*}$ & \\
\hline Ambiente 1 & ------ & $0,28^{\mathrm{ns}}$ \\
\hline Ambiente 2 & ------ & $3,53 *$ \\
\hline
\end{tabular}

${ }^{1 /}$ Avaliações realizadas aos 20 dias após a emergência da soja.

* Valores de $\mathrm{F}$ significativos a 5\% de probabilidade. ${ }^{\text {ns }}$ Valores de $\mathrm{F}$ não-significativos a 5\% de probabilidade.

A menor mortalidade de plantas de picão, observada na semeadura realizada aos $11 \mathrm{DAD}$, manteve a densidade inicial da erva equivalente à densidade constatada na pré-colheita da soja. No entanto, esse comportamento não trouxe vantagem, sob o ponto de vista de ajuste do modelo, pois foi justamente nessa época em que o ajuste demonstrou menor capacidade previsiva $\left(\mathrm{R}^{2}=0,53\right.$ no ambiente 2$)$. Assim, é possível que, na semeadura realizada aos $11 \mathrm{DAD}$, o tamanho da erva no momento da semeadura da soja seja outro fator a ser considerado, além de sua densidade, na estimativa das perdas de rendimento.

As plantas apresentam capacidade inata para auto-ajustamento quando o espaço disponível para exploração dos recursos do meio tornar-se gradativamente limitado (Radosevich et al., 1997). Esse fenômeno foi demonstrado por Yoda et al. (1963), que o denominaram "lei da potência $3 / 2$ ", segundo o relacionamento entre peso de planta e densidade que costuma ocorrer em resposta à mortalidade. Para Silvertown \& Doust (1993), a variação da população ao longo do tempo, causada pela mortalidade de plantas, somente apresenta validade em populações naturais onde não haja limite artificial de densidade. Segundo esses autores, no caso em que houver limitações naturais, como ao se utilizarem culturas anuais deliberadamente semeadas em baixas densidades, ou em situações de reduzidas infestações de ervas, em que não seja atingido o limite de recursos do ambiente, é possível que a mortalidade mostre menor importância.

Analisando a Figura 2, constata-se que, na semeadura da soja realizada mais próximo à dessecação da cobertura vegetal, a mortalidade principiou em populações mais altas, em torno de 39 plantas $\mathrm{m}^{-2}$; já nas semeaduras aos 7 e 11 DAD a mortalidade se iniciou em menores densidades, 22 e 11 plantas $\mathrm{m}^{-2}$, respectivamente. Esse resultado, embora aparentemente contraditório, mostra que a antecipação da semeadura da soja não incrementou a mortalidade da erva nas densidades baixas. Entretanto, o menor tamanho das plantas que se desenvolveram nessas épocas de semeadura permitiu que elas tolerassem densidades maiores sem ocorrer mortalidade, diferentemente do que foi observado na semeadura realizada mais tarde (11 DAD). Resultados relatados por Yoda et al. (1963) e Silvertown \& Doust (1993) indicaram que populações elevadas de ervas atingem antes o limiar de autoajuste do que populações baixas; inclusive, em populações muito esparsas, é possível elas alcançarem o rendimento final constante sem que haja qualquer mortalidade dependente da densidade. Para espécies anuais, Silvertown \& Doust (1993) afirmam que o auto-ajuste, associado à mortalidade, costuma ocorrer em 
populações superiores a 100 plantas $\mathrm{m}^{-2}$; portanto, bem superiores às populações em geral ocorrentes nesse experimento.

O ajuste propiciado pelo uso da variável massa seca, avaliado pelo $\mathrm{R}^{2}$, variou de 0,37 a 0,80 entre ambientes e épocas de semeadura da soja (Tabela 2). Excetuando-se a semeadura realizada aos 11 DAD no ambiente $2\left(R^{2}=0,80\right)$, em todas as demais situações investigadas os
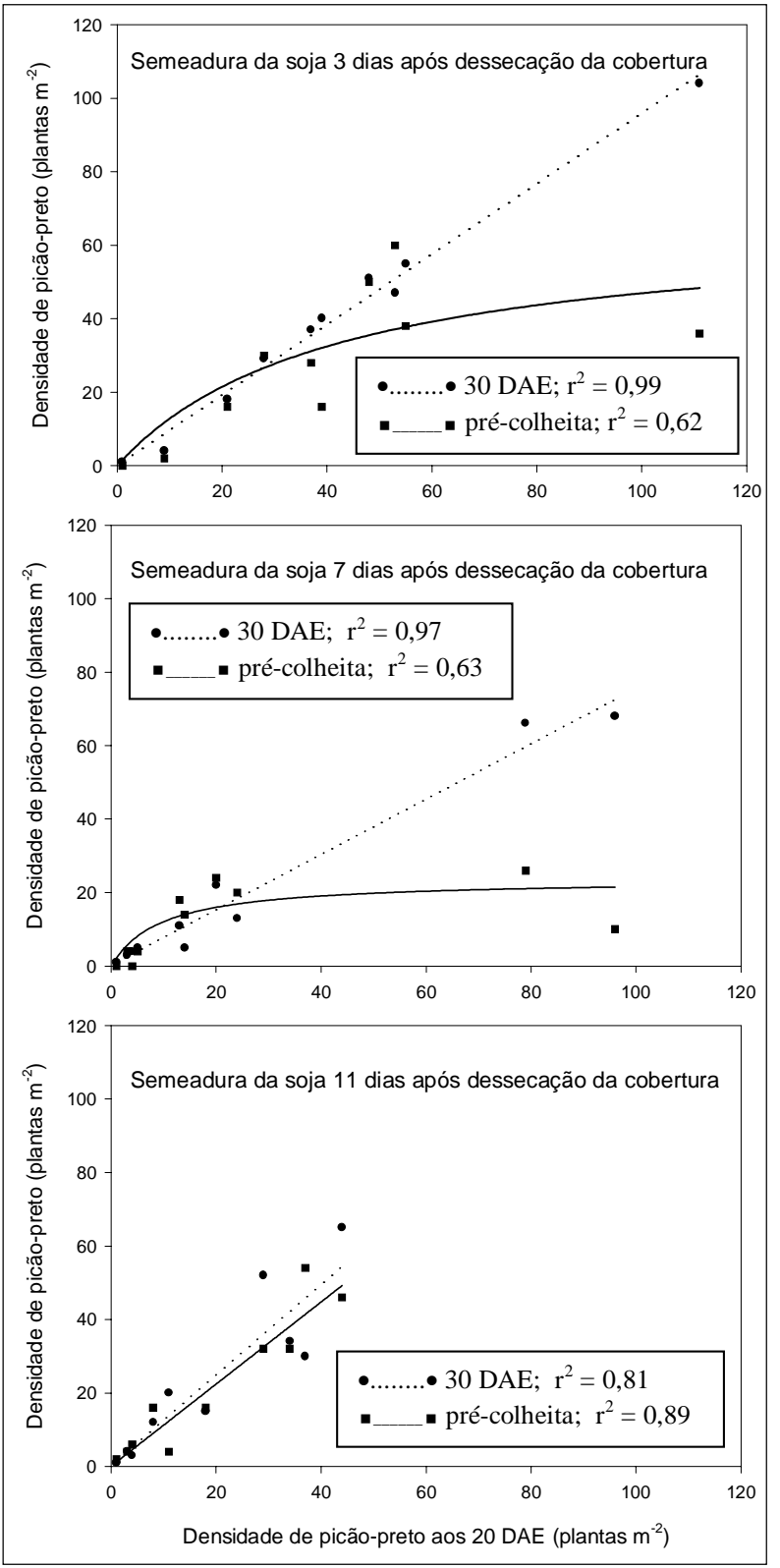

Figura 1 - Relação entre avaliações de densidade de plantas de picão-preto aos 20 e 30 dias após a emergência (DAE) e na pré-colheita da soja, Eldorado do Sul - RS, 1999/00. valores de $\mathrm{R}^{2}$ foram menores e as somas dos quadrados foram maiores do que aqueles observados para a variável densidade. Esses resultados denotam que a variável massa seca da erva foi menos apropriada do que a variável densidade para se estimar o resultado da interferência de picão em soja. No entanto, ao analisar conjuntamente os dados, percebe-se que não houve efeitos de ambientes e de épocas de semeadura quando o modelo da hipérbole foi ajustado com a variável massa seca, diferentemente do observado para densidade de plantas da erva (Tabela 2). Os resultados obtidos nesses experimentos estão em conformidade com os obtidos por Lutman et al. (1996), tanto em termos de ajustes inferiores quanto ao fato de não haver interação com ambientes, quando esses autores utilizaram a variável massa seca.

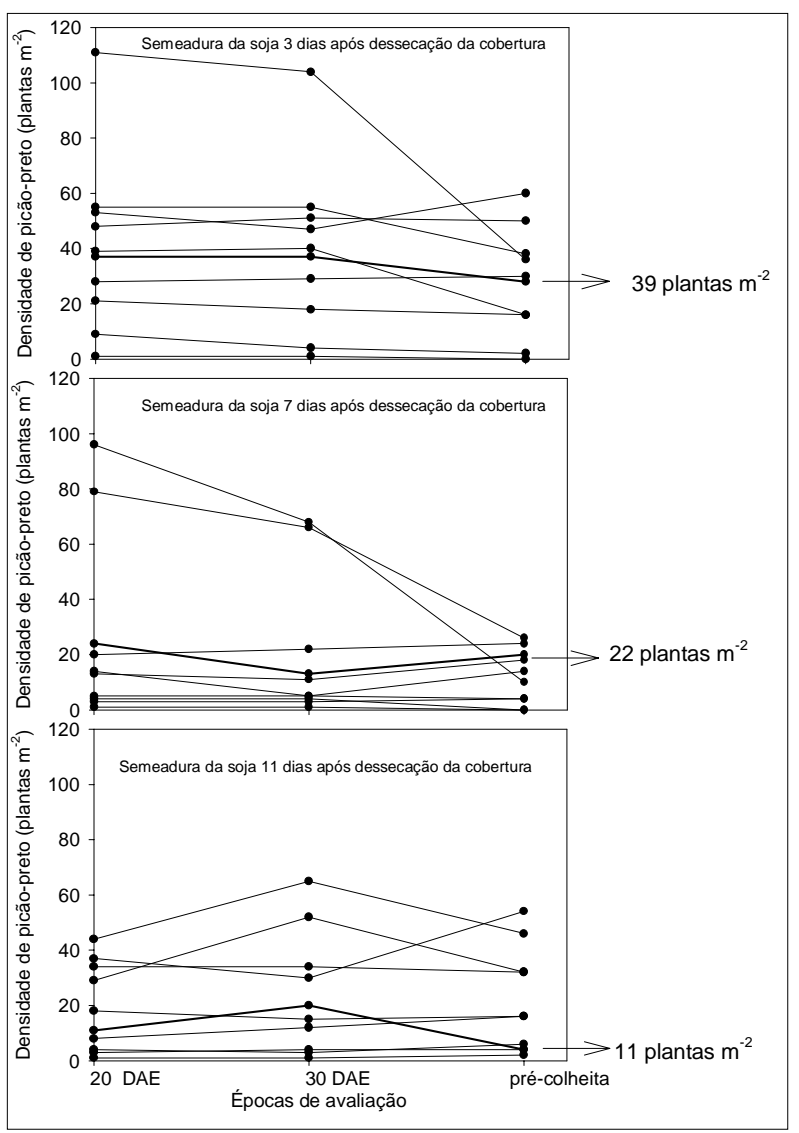

Figura 2 - Densidade de plantas de picão-preto avaliada aos 20 e 30 dias após a emergência (DAE) e na pré-colheita da soja, Eldorado do Sul - RS, 1999/00. (Linhas fortificadas e valores indicados nos retângulos referem-se densidades a partir das quais ocorreu mortalidade de ervas). 
Para a variável densidade de folhas, nas três situações avaliadas no ambiente 1 , o valor de $\mathrm{R}^{2}$ reduziu de 0,70 para 0,45 da primeira para a terceira semeadura. Ao se considerarem os valores de $\mathrm{R}^{2}$ e $\mathrm{SQR}$, verifica-se que, na primeira semeadura (3 DAD), houve melhor ajuste do modelo com a utilização de densidade de folhas, em comparação à densidade de plantas. Entretanto, houve similaridade de ajuste com essas variáveis na semeadura de 7 DAD, enquanto na última semeadura (11 DAD) o modelo foi mais bem ajustado com densidade de plantas.

A área foliar da erva como variável explicativa apresentou comportamento muito similar ao observado para densidade de folhas (Tabela 1). Os valores de $\mathrm{R}^{2}$ variaram de 0,70 a 0,47 , sendo o melhor ajuste obtido na semeadura realizada aos 3 DAD. Ao se efetuar comparação conjunta dos dados, resultou que os ajustes propiciados pelos modelos baseados na área foliar da erva, a exemplo do relatado para densidade de folhas e massa seca da erva, não diferiram entre as épocas de semeadura da soja (Tabela 2). Esses resultados mostram que essas variáveis foram mais estáveis do que a densidade da erva e foram capazes de incorporar variações na época de sua emergência, como foi apregoado por Kropff \& Spitters (1991).

O uso dos modelos baseados na área foliar e na densidade de folhas proporcionou maior capacidade previsiva do que utilizando densidade de plantas e massa seca, especialmente quando a semeadura da soja foi realizada mais próximo à dessecação da cobertura vegetal (Tabela 1). Esses resultados assemelham-se aos obtidos por Vitta \& Fernandez Quintanilla
(1996), para os quais o modelo que incorporou a variável área foliar foi tão preciso ou até mais do que o modelo baseado na densidade de ervas. No entanto, como medições de área foliar são demoradas e muitas vezes destrutivas, o uso da densidade de folhas passa a ser alternativa preferivel, por ser mais simples e rápida para avaliar. Adicionalmente, o coeficiente de correlação calculado $(0,93)$ indicou estreita associação entre área foliar e densidade de folhas quando essas variáveis foram avaliadas aos 20 DAE (Tabela 3).

Outra variável explicativa alternativa pode ser a cobertura foliar, a qual, nos estádios iniciais de desenvolvimento, associa-se à área foliar (Vitta \& Fernandez Quintanilla, 1996). Entretanto, conforme se observa na Tabela 1, a precisão do ajuste fornecido pelo uso da cobertura foliar mostrou comportamento distinto entre ambientes, o que também se observou na análise conjunta dos experimentos (Tabela 2). No ambiente 1, o uso da cobertura forneceu o melhor ajuste entre todas as variáveis para a semeadura realizada aos $7 \mathrm{DAD}$, porém foi a alternativa que forneceu os piores ajustes nas demais épocas de semeadura. No ambiente 2, obteve-se comportamento mais consistente entre épocas de semeadura; todavia, excetuando-se a de $11 \mathrm{DAD}$, nas demais épocas os ajustes propiciados pelo uso dessa variável foram inferiores aos obtidos com densidade de ervas. Essas diferenças de ajustes entre épocas de semeadura podem estar associadas à subjetividade apresentada pela avaliação visual da cobertura foliar, em que, na presença de ervas com reduzido tamanho, a sua quantificação é bastante difícil.

Tabela 3 - Coeficientes de correlação linear simples entre variáveis avaliadas para quantificar a infestação de picão-preto convivendo com soja. Passo Fundo-RS, 1998/99

\begin{tabular}{|c|c|c|c|c|c|}
\hline $\begin{array}{l}\text { Variável explicativa do } \\
\text { relacionamento }\end{array}$ & $\begin{array}{l}\text { Densidade de } \\
\text { plantas }^{\underline{1}}\end{array}$ & Massa seca $^{1^{\prime}}$ & Área foliar ${ }^{1 /}$ & 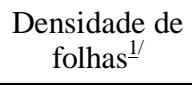 & Cobertura foliar ${ }^{1 /}$ \\
\hline Massa seca ${ }^{1 /}$ & $0,67 *$ & & & & \\
\hline Área foliar ${ }^{1 /}$ & $0,72 *$ & $0,68 *$ & & & \\
\hline Densidade de folhas ${ }^{\underline{1}}{ }^{\prime}$ & $0,88^{*}$ & $0,76^{*}$ & $0,93^{*}$ & & \\
\hline Cobertura foliar ${ }^{1 /}$ & $0,49 *$ & $0,42 *$ & $0,47^{*}$ & $0,52 *$ & \\
\hline Densidade de plantas ${ }^{2} /$ & $0,61 *$ & $0,54 *$ & $0,29 *$ & $0,47 *$ & $0,50 *$ \\
\hline
\end{tabular}

${ }^{1 /}$ Avaliada aos 20 dias após a emergência da soja. ${ }^{2 /}$ Avaliada na pré-colheita da soja.

* Significativo a $5 \%$ de probabilidade. 
Os resultados pouco promissores obtidos para cobertura foliar são reforçados pelos baixos valores de correlação observados entre essa variável e área foliar (Tabela 3) e com massa seca (Tabelas 3 e 4). Por outro lado, obtiveramse melhores coeficientes de correlação quando se correlacionou cobertura foliar, avaliada no florescimento da soja, com a densidade de plantas avaliada aos $20 \mathrm{DAE}$ ou na pré-colheita e com a massa seca da erva na pré-colheita da soja (Tabela 4). Os coeficientes de correlação obtidos com a variável cobertura foliar avaliada no florescimento da soja indicam que ela possui potencial para caracterizar a comunidade de picão. No entanto, talvez seja necessário melhorar seu método de avaliação, pois se torna difícil realizar essa estimativa em baixas densidades de ervas.

Tabela 4 - Coeficientes de correlação linear simples entre variáveis avaliadas para quantificar a infestação de picão-preto convivendo com soja. Eldorado do Sul-RS, 1999/00

\begin{tabular}{|c|c|c|c|c|c|}
\hline $\begin{array}{l}\text { Variável explicativa do } \\
\text { relacionamento }\end{array}$ & $\begin{array}{l}\text { Densidade de } \\
\text { plantas }^{\underline{1}}\end{array}$ & Massa seca ${ }^{1 /}$ & Cobertura foliar ${ }^{1 /}$ & Cobertura foliar ${ }^{2 /}$ & $\begin{array}{c}\text { Densidade de } \\
\text { plantas }^{-3 /}\end{array}$ \\
\hline Massa seca ${ }^{1 /}$ & $0,71 *$ & & & & \\
\hline Cobertura foliar ${ }^{1 /}$ & $0,41 *$ & $0,26^{\mathrm{ns}}$ & & & \\
\hline Cobertura foliar ${ }^{2 /}$ & $0,65^{*}$ & $0,54 *$ & $0,42 *$ & & \\
\hline Densidade de plantas ${ }^{-3 /}$ & $0,62 *$ & $0,46^{*}$ & $0,41 *$ & $0,84^{*}$ & \\
\hline Massa seca $a^{\frac{3}{}}$ & $0,56^{*}$ & $0,50 *$ & $0,32^{\mathrm{ns}}$ & $0,86^{*}$ & $0,94 *$ \\
\hline
\end{tabular}

${ }^{1 /}$ Avaliada aos 20 dias após a emergência da soja. ${ }^{2 /}$ Avaliada no florescimento da soja. ${ }^{3 /}$ Avaliada na pré-colheita da soja.

* Significativo a $5 \%$ de probabilidade. ${ }^{\text {ns }}$ Não-significativo a $5 \%$ de probabilidade.

Tabela 5 - Parâmetros estimados e ajustes obtidos para perdas de rendimento de grãos de soja em função de diferentes variáveis explicativas da erva picão-preto e de épocas de semeadura da soja, em Passo Fundo-RS, 1998/99 (ambiente 1), e em Porto Alegre-RS, 1999/00 (ambiente 2)

\begin{tabular}{|c|c|c|c|c|c|}
\hline \multirow{2}{*}{$\begin{array}{l}\text { Variável explicativa da } \\
\text { infestação de picão-preto }\end{array}$} & \multicolumn{2}{|c|}{ Parâmetro $^{1 /}$} & \multirow{2}{*}{$\begin{array}{c}\text { Coeficiente de } \\
\text { determinação } \\
\left(\mathrm{R}^{2}\right)\end{array}$} & \multirow{2}{*}{$\begin{array}{l}\text { Soma dos } \\
\text { quadrados do } \\
\text { resíduo }\end{array}$} & \multirow{2}{*}{ Estatística F } \\
\hline & $\mathrm{i}$ & $\mathrm{a}$ & & & \\
\hline $\begin{array}{c}\text { Ambiente 1: } \\
\text { Densidade de plantas }{ }^{2 /} \\
3 \mathrm{DAD}^{3 /} \\
7 \mathrm{DAD}^{\prime} \\
11 \mathrm{DAD}\end{array}$ & $\begin{array}{l}2,97 \\
6,38 \\
8,41\end{array}$ & $\begin{array}{l}45,5 \\
32,3 \\
33,8\end{array}$ & $\begin{array}{l}0,81 \\
0,46 \\
0,17\end{array}$ & $\begin{array}{r}544,6 \\
2.202,6 \\
4.955,1\end{array}$ & $\begin{array}{l}98,0 * \underline{5} \\
28,4^{*} \\
18,8 *\end{array}$ \\
\hline $\begin{array}{c}\text { Ambiente } 2: \\
\text { Densidade de plantas }{ }^{2 /} \\
3 \mathrm{DAD}^{3 /} \\
7 \mathrm{DAD}^{\prime} \\
11 \mathrm{DAD}\end{array}$ & $\begin{array}{l}2,71 \\
5,71 \\
8,77\end{array}$ & $\begin{array}{l}32,6 \\
42,3 \\
53,6\end{array}$ & $\begin{array}{l}0,77 \\
0,62 \\
0,64\end{array}$ & $\begin{array}{r}344,4 \\
952,7 \\
1.499,9\end{array}$ & $\begin{array}{l}58,2 * \\
31,7 * \\
40,3 *\end{array}$ \\
\hline $\begin{array}{r}\text { Cobertura foliar }{ }^{4 !} \\
3 \mathrm{DAD}^{3 /} \\
7 \mathrm{DAD}^{1 /} \mathrm{DAD}\end{array}$ & $\begin{array}{l}1,40 \\
1,67 \\
1,97\end{array}$ & $\begin{array}{c}50,2 \\
110,0 \\
66,5\end{array}$ & $\begin{array}{l}0,75 \\
0,82 \\
0,72\end{array}$ & $\begin{array}{r}365,7 \\
451,1 \\
1.155,0\end{array}$ & $\begin{array}{l}54,1 * \\
71,9 * \\
53,5^{*}\end{array}$ \\
\hline $\begin{array}{l}\text { Massa seca } \\
3 \mathrm{DAD}^{3 /} \\
7 \mathrm{DAD}^{\underline{2}} \\
11 \mathrm{DAD}^{\prime}\end{array}$ & $\begin{array}{l}0,71 \\
0,97 \\
0,40\end{array}$ & $\begin{array}{l}26,3 \\
37,3 \\
60,6\end{array}$ & $\begin{array}{l}0,71 \\
0,47 \\
0,67\end{array}$ & $\begin{array}{r}418,8 \\
1.315,9 \\
1.414,0\end{array}$ & $\begin{array}{l}46,7 * \\
21,7 * \\
42,9 *\end{array}$ \\
\hline
\end{tabular}

${ }^{1 /} \mathrm{i}$ = porcentagem de perda de rendimento por unidade da erva quando sua densidade se aproxima de zero; $\mathrm{a}=$ porcentagem de perda de rendimento quando a densidade da erva tende ao infinito. ${ }^{2 /}$ Avaliação realizada na pré-colheita da soja. ${ }^{3 /}$ Época de semeadura da soja em dias após a dessecação da cobertura vegetal. ${ }^{4 /}$ Avaliação realizada no florescimento da soja. ${ }^{5 /}$ Indica significância a $5 \%$ de probabilidade. 
A utilização da cobertura foliar avaliada no florescimento da soja permitiu melhorar consideravelmente a qualidade do modelo da hipérbole aos dados, com valores de $\mathrm{R}^{2}$ superiores a 0,70 para as três épocas de semeadura da soja (Tabela 5). Entretanto, esses resultados, sob o ponto de vista de implementação de medidas de controle, são pouco úteis. Eles serviriam apenas como referencial para utilização como variável explicativa de perdas de rendimento causadas pela presença de picão, além de serem úteis para eventuais estimativas tardias de perdas de rendimento causadas por ervas que não foram controladas ou escaparam do controle.

De forma geral, a precisão das estimativas de perda de rendimento de grãos de soja por avaliações realizadas no início do ciclo poderia ser melhorada se fossem utilizadas características morfológicas da erva; contudo, a variação devida às condições meteorológicas subseqüentes poderá persistir como incógnita. Aliado a isso, características morfológicas avaliadas aos 20 DAE em geral ainda não refletem efeitos da interferência entre plantas, provavelmente porque a interferência ainda não tenha se iniciado ou porque alterações morfológicas ainda não se manifestaram. Assim, características morfológicas, embora contemplem possiveis diferenças entre épocas de emergência das ervas, como está caracterizado na Tabela 2 , podem manter alguns dos problemas observados para a variável densidade; ou seja, essas variáveis não são suficientemente hábeis em estimar possíveis reduções no crescimento das ervas ou mesmo predizer sua mortalidade.

Vale a pena enfatizar que algumas das variáveis testadas representam na verdade relações de área foliar ou massa seca por planta com a densidade existente na área amostrada. Diante do exposto, sugere-se utilizar variáveis que antecipem algum grau de interferência, ou que se mantenham relativamente estáveis quando ocorrer intensificação da interferência. Nesse contexto, é possível que variáveis que contemplem as proporções relativas das espécies, expressas tanto em massa seca quanto em área foliar das ervas e da cultura, sejam utilizadas com maior poder em estimar as perdas de rendimento causadas pelas ervas.

\section{LITERATURA CITADA}

ALDRICH, R. J. Predicting crop yield reductions from weeds. Weed Technol., v. 1, n. 3, p. 199-206, 1987.
BUSSLER, B. H.; MAXWELL, B. D.; PUETTMANN, K. J. Using plant volume to quantify interference in corn (Zea mays) neighborhoods. Weed Sci., v. 43, n. 4, p. 586-594, 1995.

EMPRESA BRASILEIRA DE PESQUISA

AGROPECUÁRIA - EMBRAPA. Centro Nacional de Pesquisa de Solos. Sistema brasileiro de classificação de solos. Brasília: 1999. 412 p.

FLOREZ, J. A. et al. Predicting rice yield losses caused by multispecies weed competition. Agron. J., v. 91, n. 1, p. 8792, 1999.

GOMEZ, K. A.; GOMEZ, A. A. Statistical procedures for agricultural research. 2.ed. New York: Wiley, 1984. 680 p.

KROPFF, M. J.; LOTZ, L. A .P. Optimization of weed management systems: the role of ecological models of interplant competition. Weed Technol., v. 6, n. 2, p. 462470, 1992.

KROPFF, M. J.; SPITTERS, J. T. A simple model of crop loss by weed competition from early observations on relative leaf area of the weeds. Weed Res., v. 31, n. 2, p. 97-105, 1991.

LOTZ, L. A. P. et al. Techniques to estimate relative leaf area and cover of weeds in crops for yield loss prediction. Weed Res., v. 34, n. 3, p. 167-175, 1994.

LUTMAN, P. J. W. et al. Prediction of competition between oilseed rape and Stellaria media. Weed Res., v. 40, n. 3, p. 255-269, 2000.

LUTMAN, P. J. W.; RISIOTT, R.; OSTERMANN, H. P. Investigations into alternative methods to predict the competitive effects of weeds on crop yields. Weed Sci., v. 44 , n. 2 , p. $290-297,1996$.

NGOUAJIO, M.; LEMIEUX, C.; LEROUX, G. D. Prediction of corn (Zea mays) yield loss from early observations of the relative leaf area and the relative leaf cover of weeds. Weed Sci., v. 47, n. 3, p. 297-304, 1999.

OLIVER, L. R.; FRANS, R. E.; TALBERT, R. E. Field competition between tall morningglory and soybean. I.Growth analysis. Weed Sci., v. 24, n. 5, p. 482-488, 1976.

RADOSEVICH, S.; HOLT, J.; GHERSA, C. Associations of weeds and crops. In: Weed ecology: implications for management. 2. ed. New York: John Wiley, 1997. p. 163214.

INSTITUTE STATISTICAL ANALYSIS SYSTEM - SAS. User's guide: version 6. 4.ed. Cary: SAS Institute, 1989. $846 \mathrm{p}$. 
SILVERTOWN, J. W.; DOUST, J. L. Intraspecific interactions. In: INTRODUCTION to plant population biology. Oxford: Blackwell, 1993. p. 51-71.

SPADOTTO, C. A. et al. Avaliação de parâmetros para o monitoramento da interferência de plantas daninhas na cultura da soja (Glycine max L.). Planta Daninha, v. 10, n. 1-2, p. 33-38, 1992.

VITTA, J. I.; FERNANDEZ QUINTANILLA, C. Canopy measurements as predictors of weed-crop competition. Weed Sci., v. 44, n. 3, p. 511-516, 1996.
VITTA, J. I.; SATORRE, E. H.; LEGUIZAMON, E. S. Using canopy attributes to evaluate competition between Sorghum halepense (L.) Pers. and soybean. Weed Res., v. 33, n. 1, p. 88-97, 1993.

WEAVER, S. E. Size-dependent economic thresholds for three broadleaf weed species in soybeans. Weed Technol., v. 5, n. 3, p. 674-679, 1991.

YODA, K. et al. Self-thinning in overcrowded pure stands under cultivated and natural conditions - intraspecific competition among higher plants. J. Biol. Osaka City Univ., v. 14, p. 107-129, 1963. 